\title{
Mechanized Method to Inoculate Field Soil to Evaluate Fusarium Crown Rot of Wheat
}

\author{
Richard W. Smiley ${ }^{\dagger}$ \\ Columbia Basin Agricultural Research Center, Oregon State University, Pendleton, OR 97801
}

\begin{abstract}
Assessments of Fusarium crown rot are often made in field trials inoculated with Fusarium pseudograminearum or $F$. culmorum. Factors affecting the efficiency of two inoculation procedures were evaluated. Pulverized Fusarium-colonized wheat plus oat grain inoculum mixed with the wheat seed caused more seedling damping-off compared with equal rates of colonized whole millet seeds placed $2 \mathrm{~cm}$ above the wheat seed. Both inoculation systems increased the incidence and severity of crown rot. The efficiency of

plots became greater when starter fertilizer was applied with or below the wheat seed and when soil below the wheat seed was disrupted by a seed drill with an opener that creates a groove or trench directly below the seed. No biologically important associations were detected between whiteheads and other measures of crown rot, grain yield, or grain test weight. The millet seed inoculation system was the most efficient for wheat production systems in the semiarid U.S. Pacific Northwest.
\end{abstract} $F$. pseudograminearum-colonized millet seed inoculum was not reduced when wheat seed was treated with difenoconazole. Crown rot in inoculated
Keyword: Fusarium isolate aggressiveness
Fusarium crown rot (crown rot) of wheat (Triticum aestivum L.) is caused by a complex of soilborne species, of which the most important are Fusarium pseudograminearum (O'Donnell \& Aoki) and $F$. culmorum (Wm. G. Sm.) Sacc. (Cook 1968, 1980, 1981; Poole et al. 2013; Smiley and Patterson 1996). In the semiarid wheat belt of U.S. Pacific Northwest states (Idaho, Oregon, and Washington), crown rot can reduce wheat yields by an average of $10 \%$ (range, 0 to $35 \%$ ) in commercial winter wheat fields (Smiley et al. 2005b). Contributing factors to the high economic importance of crown rot include (i) low and irregular mean annual precipitation, (ii) precipitation during winter but not summer, (iii) high residue-retention conservation farming practices, and (iv) 2-year winter wheat-fallow monocultures (Alahmad et al. 2018; Burgess et al. 1993; Cook 1981; Ogg et al. 1999; Schillinger et al. 2006; Smiley 1996, 2009a; Smiley and Patterson 1996; Smiley et al. 1996, 2009; Summerell et al. 1989).

$F$. pseudograminearum and $F$. culmorum survive between wheat crops as mycelium and chlamydospores in dead stems and plant crowns (Burgess et al. 2001; Cook 1981). Distribution of Fusarium inoculum in soil is spatially heterogeneous. Inoculation techniques have been used to minimize heterogeneity within experiments and to amplify the incidence and severity of crown rot to improve distinctions among experimental variables. Inoculation of field trials in other regions has been performed with pathogen-infested substrates of wheat chaff and kernels of corn, wheat, barley, or oat or their mixtures (Burgess and Liddell 1983; Kane et al. 1987; Liddell et al. 1986; Wildermuth and McNamara 1994). These substrates were sterilized, colonized by a pathogen, air-dried, ground to various particle sizes, and dispensed as inoculum into soil. The ground inoculum consisted of a wide range of particle sizes (e.g., CFUs), did not flow freely, and had to be mixed with seed or dispensed manually into seeded plots.

${ }^{\dagger}$ Corresponding author: R. W. Smiley; richard.smiley@oregonstate.edu

Funding: This research was supported by funds from the Oregon Wheat Commission and the U.S. Department of Agriculture Agricultural Research Service Root Disease and Biological Control Research Unit in Pullman, Washington.

The author(s) declare no conflict of interest.

Accepted for publication 21 May 2019.

(C) 2019 The American Phytopathological Society
When inoculum is mixed with the seed, the rate of inoculum must be adequate to at least ensure a moderate rate of infection but less than that which causes pre-emergence damping-off of seedlings (Liddell et al. 1986). Isolates of $F$. pseudograminearum and $F$. culmorum collected from symptomatic wheat plants in Oregon and Washington (Smiley and Patterson 1996) exhibit a wide range of aggressiveness to wheat in the greenhouse and spring wheat in the field (Smiley et al. 2005a). The appropriate rate of inoculum applied with the wheat seed varies from season to season and from field to field, depending on unpredictable factors associated with soil moisture and temperature, and aggressiveness of the pathogen isolate. Periodic severe damping-off led to placement of inoculum into a layer above the wheat seed, but the inoculum still needed to be dispensed manually and incorporated into soil (Dodman and Wildermuth 1987; Wildermuth and McNamara 1994). The wheat coleoptile emerged through the infested layer and became infected in a more natural manner, which mostly eliminated the damping-off hazard.

Smiley et al. (2005b) used whole millet seeds as the inoculum substrate to more precisely define the number of Fusarium inoculum foci per unit of row length. Initially, the millet-based inoculum was distributed manually over wheat rows immediately after the wheat was sown. Later, a seed drill was modified so millet-based inoculum could be metered into soil and placed several centimeters above the wheat seed at the time of planting. The inoculum was metered from a fertilizer dispenser mounted on the drill and deposited into soil through a tube that was separate from the tube used for the wheat seed. The real-time simultaneous inoculum dispersal system was used for subsequent field studies (Smiley and Yan 2009; Smiley et al. 2005a, b) but the formative process for choosing and calibrating that system has not been described.

Infection of wheat by these species of Fusarium often results in a lesion on the subcrown internode that can be scored for incidence and severity. More severe crown rot causes rotting of crowns, which can be visualized by splitting the crowns to determine whether internal tissue is abnormally brown. Severe crown rot also causes browning of lower stem internodes, which can be visually scored for incidence or severity. The most conspicuous and easily quantified symptom of crown rot is a premature senescence of heads ("whiteheads") that occurs when grain kernels are transitioning from the milk to dough stage. Each symptom is strongly influenced by a different set or timing of environmental conditions. Stem browning is the most reliable symptom for visually quantifying crown rot incidence and severity (Burgess et al. 2001), but it is also the most labor-intensive process and is most accurate when done at the time of plant anthesis. 
However, stem browning is typically and most conveniently quantified on stubble after harvest, at which time it is sometimes poorly correlated with reduced grain yield (Knight and Sutherland 2015; Smiley et al. 2005b). Counting whiteheads is much more rapid than scoring other crown rot symptoms.

The objectives of this article were to assess the influences of several Fusarium inoculation procedures on the development of crown rot under field conditions. Four experiments evaluated the type, rate and placement of inoculum, differences among isolates of $F$. pseudograminearum and $F$. culmorum, treatment of seeds with protectant fungicides, and application of starter fertilizer with different types of drill openers.

\section{Materials and Methods}

Experimental sites. Selected Fusarium crown rot data were taken from experiments that were performed on wheat fields near the eastern Oregon communities of Echo (Morrow County; 45.6416, -119.4537), Moro (Sherman County; 45.4852, -120.7167), and Pendleton (Umatilla County; 45.7120, -118.6278). Characteristics of the locations were described by Smiley and Patterson (1996). Elevations ranged from 340 to $540 \mathrm{~m}$. Mean annual precipitation ranged from 282 to $442 \mathrm{~mm}$, with most occurring from October through May. All soils were deep silt loams (Typic Haploxerolls).

A mixture of $F$. pseudograminearum and $F$. culmorum is endemic and spatially heterogeneous in the prevailing wheat-fallow production system. The dominant species varies with environmental and crop management factors (Poole et al. 2013; Smiley and Patterson 1996; Smiley et al. 2013, 2016). No attempt was made to quantify the native pathogens at each site because $F$. pseudograminearum was most prevalent and survives as mycelium in pieces of crop refuse that are not easily quantifiable (Burgess et al. 2001; Cook 1981). The pathogens at each location were periodically isolated and identified morphologically (Nelson et al. 1983) from infested pieces of browned stubble after the previous harvest.

This article includes unpublished data from three experiments that identified factors that influenced the performance of Fusarium inoculum in field trials with winter wheat. Individual subheadings describe the principal treatment effect examined in this work.

Inoculum substrate, rate, and placement. The inoculum substrate, application rate, and placement relative to wheat seed was examined over a period of two winter wheat crop years: 1996 and 1997. During 1996, inoculum of $F$. pseudograminearum (isolate 34-15) was grown on two presterilized substrates, either millet seeds or a mixture of wheat and oat kernels. The pathogen was isolated from an infested winter wheat crown (Smiley and Patterson 1996) and identified using morphological features of a single spore colony growing on half-strength potato dextrose agar and wheat leaf agar media (Nelson et al. 1983). The isolate was stored at $4{ }^{\circ} \mathrm{C}$ on autoclaved barley seed. It was prepared as inoculum as described by Burgess and Liddell (1983). Colonies growing on one-fifth-strength potato dextrose agar medium were cut into $3-\mathrm{mm}$ squares and transferred into flasks containing a twice-autoclaved mixture (50:50, by weight) of wheat and oat kernels. Flasks were shaken intermittently for 2 weeks to reduce clumping. The thoroughly colonized grain mixture was air-dried at room temperature (approximately $24^{\circ} \mathrm{C}$ ) in paper bags. Dried grains were then ground in a Wiley Mill to pass through a 4-mm sieve. A second type of inoculum consisted of the pathogen being increased on twice-autoclaved millet seeds. The dried millet seeds were sieved to produce a whole-seed inoculum substrate with approximately 200 seeds per gram.

The fields were fertilized with anhydrous ammonia using a shank applicator prior to planting. Seed of winter wheat cultivar Rod was planted during early October 1995 at a rate of $194 \mathrm{seeds} / \mathrm{m}^{2}$. Seed was not treated with a fungicide. Plantings at Moro and Pendleton were at 8 - and 5-cm depths, respectively. At each location, wheat seed was placed $2 \mathrm{~cm}$ into moist soil below a variable depth overburden of air-dry soil (dust mulch) using a four-row John Deere HZ splitpacker deep-furrow drill with hoe-type row openers at 36-cm spacing (Fig. 1A). The commercial drill chassis was modified for small-plot research as described by Vogel (1978). Seed was metered into rows using a ground-driven cone planter connected to a Zero-Max Adjustable Speed Drive (Zero-Max Inc., Plymouth, MN). The drive was used to calibrate the cone to complete one rotation over the desired plot length. Seed between baffles in the rotating cone was dropped through an electric spinner and manifold to divide the seed equally into the four tubes leading to each drill opener.

The experiment consisted of three replicates of three variables: two locations, two inoculum types, and 10 inoculum rates. The locations were near Moro and Pendleton. The two types of inoculum were dispensed at rates of $0,0.1,0.2,0.3,1.0,1.7,3.3,8,16$, and $33 \mathrm{~g} / \mathrm{m}$ of row length. The control consisted of $8 \mathrm{~g}$ of sterilized noninfested substrate per meter of row. The control was prepared in the manner described for the inoculum, without colonization by the fungus. Plots were $1.5 \mathrm{~m}$ wide and $6 \mathrm{~m}$ long. Replicates were placed side to side into a $6 \times 90-\mathrm{m}$ experimental area.

The pulverized grain substrate was measured into packets containing the wheat seed, and the mixture was dispensed through the cone on the drill. For the millet substrate, the wheat seed was planted into drill strips and millet seeds were then manually distributed over the rows and shallowly incorporated into the surface (a powdery-dry dust mulch) using a garden rake. After planting, herbicides were applied in accordance with industry standards to kill broadleaf weed species that emerged during the spring (March).

Seedling density was counted in two 1-m row lengths of each plot during mid-October 1995. Each row section was marked with flags. Whiteheads and total heads were counted in the same row sections during mid-June 1996. Six samples of crown rot-affected plants were collected and isolations were made to confirm that whiteheads were caused by $F$. pseudograminearum. Grain was not harvested.

The experiment was analyzed as a three-way randomized block with location as the main plot, inoculum substrate and placement as the subplot, inoculum rate as the sub-subplot, and replicates as blocks. Data for the percentage of whiteheads were normalized using the arcsine transformation $(\operatorname{arcsine} \sqrt{ }[\% / 100])$ and seedling density was normalized by applying the square root transformation. Analyses were conducted using CoStat statistical software (version 6.4; CoHort Software, Monterey, CA). Means were separated using Fisher's least significant difference test $\left(\mathrm{LSD}_{0.05}\right)$.

The millet seed inoculation system was repeated in a modified form at Pendleton during the 1996 to 1997 crop year. The pulverized grain substrate was not re-evaluated because damping-off in that treatment was severe during the first year. Five isolates of $F$. pseudograminearum (93-82-03, 94-006-13, 94-32-06, 94-44-09, and 94-81-11) were identified morphologically as described previously and were confirmed using PCR (Williams et al. 2002). The isolates were stored on silica beads at $4^{\circ} \mathrm{C}$ and on autoclaved barley seed at $-80^{\circ} \mathrm{C}$. Three isolates were from Sherman and Wasco counties in Oregon, and two isolates were from Walla Walla County in Washington. They exhibited aggressiveness ratings from 4.8 to 6.0 on a 0 to 7 scale in a greenhouse test with winter wheat cultivar Stephens seedlings grown in a greenhouse (unpublished data), in which 0 indicated no damage to seedlings and 7 indicated strong crown rot symptom development and stunting of seedling growth. Each isolate was increased in individual flasks of millet seeds, dried, and then mixed in equal proportions to prepare inoculum for the field trial.

The experimental area was fertilized and managed as described for the first year. This experiment consisted of four inoculum rates $(0$, $0.5,1.6$, and $4 \mathrm{~g} / \mathrm{m}$ of row) replicated six times. Plots were $1.5 \mathrm{~m}$ wide and $12.2 \mathrm{~m}$ long. Replicates were placed side by side into a $12.2 \times 36-\mathrm{m}$ area. Winter wheat cultivar Stephens was planted at a rate of 190 seeds $/ \mathrm{m}^{2}$ during late September 1996 using the same deep-furrow seed drill. Seed was planted at 5-cm depth into moist soil below an overburden of air-dry soil (dust mulch). Wheat seeds were treated with benomyl (Benlate, $0.225 \mathrm{~g}$ of active ingredient [a.i.]/kg of seed; DuPont Crop Protection, Wilmington, DE), as suggested by Wildermuth and McNamara (1994).

The mixed-isolate millet seed substrate was metered from a fourrow Gandy Multi-Purpose Seed/Fertilizer/Granular Chemical Applicator (Gandy Company Inc., Owatonna, MN) mounted on the seed drill and operated by a Zero-Max Adjustable Speed Drive (Fig. 1B). 


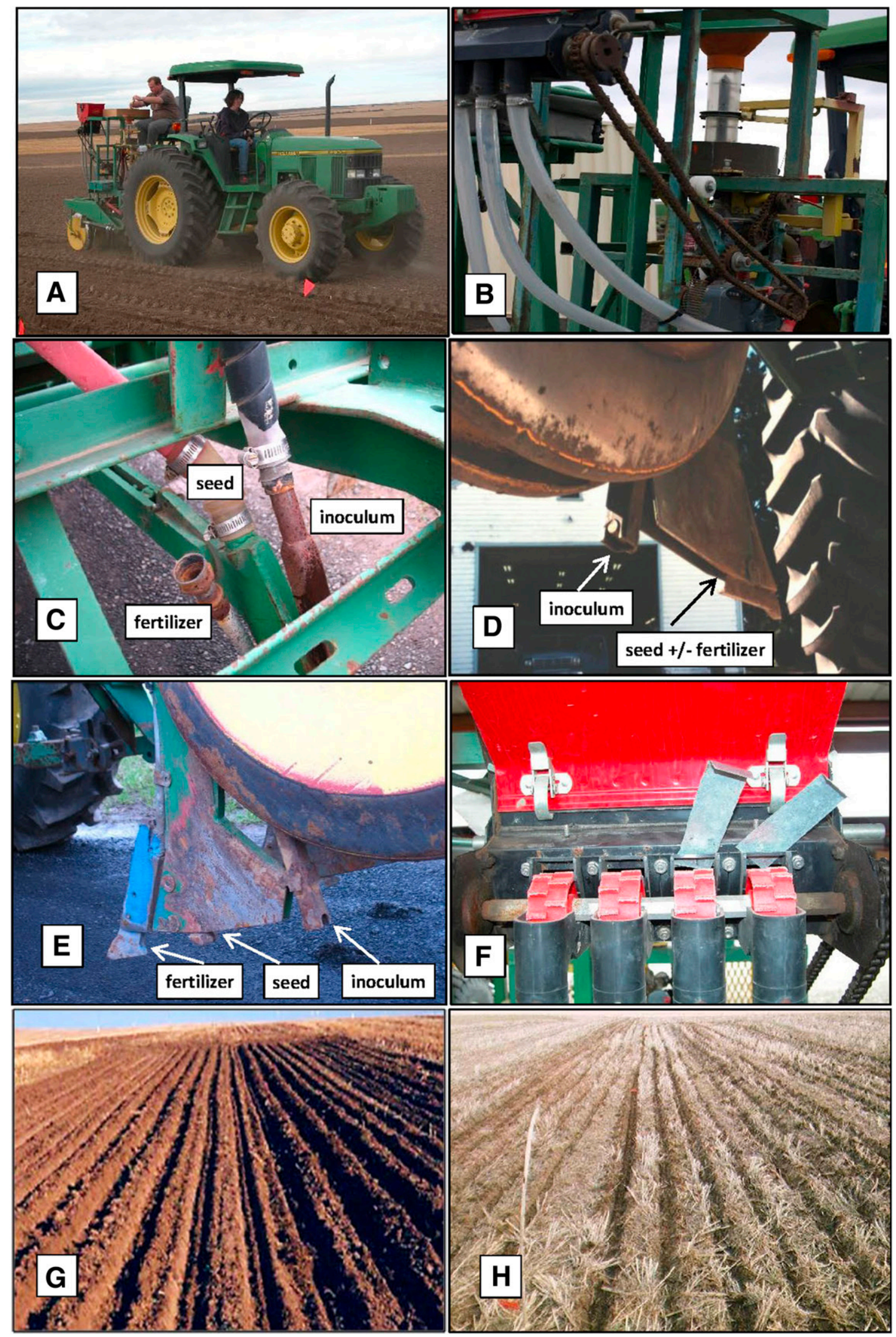

Fig. 1. Modification of a John Deere $\mathrm{HZ}$ seed drill for small-plot placement of wheat seed through a rotating seed cone and either inoculum of Fusarium-infested whole millet seeds or starter fertilizer through a fertilizer distributor. A, Overview of drill and mechanized inoculation system. B, Detail of inoculum or fertilizer distributor and chain-driven adjustablespeed drive. C, Detail of a flexible tube connected to a copper shaft mounted behind the row-opener boot for placing inoculum above the wheat seed (alternatively, the flexible tube can be connected to the other shaft that is mounted in front of the row-opener boot for placing fertilizer below or in the seed row depending on which row-opener point is installed). $D$, Row-opener boot with the standard row-opener point installed and the trailing inoculum-delivery shaft extended downward for photographic clarity (during operation, the shaft is adjusted upward to place inoculum above the seed). E, Extended row-opener point used to place fertilizer below the seed and the trailing shaft used to place inoculum above the seed. F, Optional blocking plates can be inserted into slots in the distributor to allow placement of inoculum or fertilizer only into selected rows of the four-row drill. G, A cultivated seedbed with seed placed into moist soil at 12-cm depth below a 10-cm-deep dust mulch (press wheels formed 6-cm deep furrows that enabled seedlings to emerge from 12-cm depth through only $6 \mathrm{~cm}$ of soil). $\mathrm{H}$, A nontilled seedbed with seed placed at 3-cm depth into mineral soil below a thick layer of flail-mowed wheat stubble. 
The inoculum was dispensed from the applicator into tubes mounted behind each drill opener and separate from the tubes used to dispense the wheat seed from the seed cone (Fig. 1C). Inoculum was placed $2 \mathrm{~cm}$ above the wheat seed (Fig. 1D). Seedling density and counts of whiteheads and total heads were as described previously.

The experiment was analyzed as a two-way randomized block with inoculation (plus or minus) as the main plot, inoculum rate as the subplot, and replicates as blocks. Data for the percentage of whiteheads and seedling density were normalized and means were separated as described earlier.

Fungicide seed treatments. Treatment of seed with benomyl was recommended to reduce or eliminate seedling damping-off when wheat was grown in trials inoculated with $F$. pseudograminearum in Australia (Wildermuth and McNamara 1994). Nearly all wheat seed in the Pacific Northwest was treated with difenoconazole plus mefenoxam. It was not known whether difenoconazole would affect the expression of whiteheads. Seed treatments with benomyl and difenoconazole were compared with and without added inoculum of $F$. pseudograminearum in a field near Echo during the 1997 to 1998 winter wheat crop year. The experiment was repeated near Moro during the 2001 to 2002 crop year.

The experiment consisted of five replicates of two inoculum treatments (plus or minus) and three seed treatments. The inoculum treatment consisted of millet-based substrate containing a mixture of the five isolates of $F$. pseudograminearum described for the previous experiment. Inoculum was dispensed through the deep-furrow drill at a rate of $2.3 \mathrm{~g} / \mathrm{m}$ of row and $2 \mathrm{~cm}$ above the wheat seed. The noninoculated control consisted of an equal quantity of sterilized millet seeds that were not infested with the pathogen. Inoculated and noninoculated treatments were placed into adjacent drill rows. Seed treatments occurred side by side within adjacent inoculated or noninoculated drill rows. The treatments were benomyl (Benlate $50 \mathrm{~W}$ ) applied at $0.225 \mathrm{~g}$ of a.i./kg of seed, difenoconazole plus mefenoxam (Dividend XL plus Ridomil) applied at 24.2 plus $0.09 \mathrm{~g}$ of a.i./kg of seed, or no fungicide applied to seed. The experiment was planted to winter wheat cultivar Stephens during October 1997 and 2001. Data were collected for seedling emergence and percentages of whiteheads.

Data were normalized before analysis, as described previously. The experiment was analyzed separately for locations (years) because percentages of whiteheads were much greater at Moro (year 2) than at Echo (year 1). The experiment was analyzed as a split plot with inoculum as the main plot and seed treatments as the subplot.

Starter fertilizer and root-zone tillage. This experiment was conducted over two spring wheat crop years (1997 and 1998) on a field near Echo. The goal was to evaluate the influence of starter fertilizer banded with or below the wheat seed. The experiment included five replicates of 2 years, two inoculum treatments (plus or minus), two starter fertilizer treatments (plus or minus), and two root-zone tillage treatments (plus or minus). Plots were $12.2 \mathrm{~m}$ long and $1.5 \mathrm{~m}$ wide and were arranged as five randomized complete blocks each containing eight treatments. The five $12.2 \times 12$-m replicates were arranged side by side into a $12.2 \times 60-\mathrm{m}$ area. The area was prepared each year by applying a uniform application of urea ammonium nitrate solution (Solution 32;62 kg of $\mathrm{N} / \mathrm{ha}$ ) using a spoke-wheel injector.

Seed of spring wheat cultivar Westbred 936 was treated with difenoconazole plus mefenoxam fungicides (Dividend XL plus Ridomil, 24.2 plus $0.09 \mathrm{~g}$ of a.i./kg of seed) and imidacloprid insecticide (Gaucho, $0.8 \mathrm{~g}$ of a.i. $/ \mathrm{kg}$ ) and planted during mid-March into moist soil at 3 -cm depth. The deep-furrow drill used for these experiments had two types of interchangeable furrow openers (Fig. 1D and E). The manufacturer's standard opener applied the starter fertilizer directly into the wheat seed zone without disturbing soil below that zone. The modified (extended) opener applied the fertilizer $2.5 \mathrm{~cm}$ below the wheat seed, resulting in soil disturbance below the seed even when fertilizer was not being applied; use of the extended opener is subsequently referred to as root-zone tillage. The two styles of drill opener were compared with or without dispensing starter fertilizer.
Starter fertilizer was a mixture of ammonium phosphate-sulfate (16-20-0-24) and potassium chloride (0-0-60), delivered at $\mathrm{N}$, $\mathrm{P}_{2} \mathrm{O}_{5}, \mathrm{~K}_{2} \mathrm{O}$, and $\mathrm{S}$ rates of $9.0,11.2,8.6$, and $13.5 \mathrm{~kg} / \mathrm{ha}$, respectively.

Two passes of the drill were used to establish the plots. In the first pass, eight plots were planted to wheat in each replicate. Duplicate sets of plots received all four combinations of root-zone tillage and starter fertilizer. The drill was cleaned, the standard opener points were installed, and the empty drill was adjusted to disturb only the surface $1 \mathrm{~cm}$ of the soil as it was passed again over half the plots that were to remain noninoculated. Millet-based inoculum consisting of the mixture of six isolates of $F$. pseudograminearum was then dispensed at a rate of $2.3 \mathrm{~g} / \mathrm{m}$ of row through the seed cone into the remaining half of the plots. The drill incorporated inoculum into the surface $1 \mathrm{~cm}$, about $2 \mathrm{~cm}$ above the wheat seed.

Seedling density was counted in late March and plant samples were dug in late May to evaluate the incidence and severity of lesions on subcrown internodes and the incidence of plants exhibiting a browning of the internal crown tissue. Whiteheads and total heads were counted during mid-June and grain was harvested during mid-July to measure grain yield and test weight. The experiment was repeated on a nearby field during the second year (1998).

Data for whiteheads, subcrown internode lesions, and brown culms were transformed using the arcsine transformation. Data for seedling density, grain yield, and grain test weight were transformed using the square root transformation. The experiment was analyzed as described in the Results.

\section{Results}

Inoculation substrate, rate, and placement. During the first crop year (1995 to 1996), seedling density was significantly $(P<0.0001)$ affected by all three main effects (location, inoculum rate, and inoculum type and placement) and by interactions of location $\times$ type $(P=$ $0.0397)$ and rate $\times$ type $(P<0.0001)$. When millet inoculum was placed $2 \mathrm{~cm}$ above the wheat seed, there was no effect of inoculum rate on seedling density (Fig. 2A). When ground wheat plus oat inoculum was placed with the seed, seedling damping-off occurred at both locations and the intensity of damping-off increased as the rate of inoculum was increased (Fig. 2A).

Percentages of whiteheads were strongly $(P<0.0001)$ affected by each of the main effects and the inoculum rate $\times$ placement interaction. Whitehead percentages were greater at Moro than at Pendleton for each of the inoculum placement options (Fig. 2B). When inoculum was placed above the seed, percentages of whiteheads were at a maximum over the inoculum range of 8 to $33 \mathrm{~g} / \mathrm{m}$ of row at Moro, and they increased continuously in the range of 1.7 to $33 \mathrm{~g} / \mathrm{m}$ of row at Pendleton. Whiteheads were sharply increased at both locations by adding inoculum at rates as low as $1.7 \mathrm{~g} / \mathrm{m}$ either above the seed or with the seed. When inoculum was placed with the wheat seed, there were increasing percentages of whiteheads until a maximum was attained at an inoculation rate of $8 \mathrm{~g} / \mathrm{m}$ at both locations. Percentages of whiteheads then decreased dramatically at the two highest rates of ground inoculum, presumably owing to the reduced plant densities and reduced competition for stored soil water by fewer surviving plants. Whiteheads were unrelated to plant density when the inoculum was placed above the wheat seed (Fig. 2C). In contrast, when ground inoculum was placed with the wheat seed, the percentage of whiteheads increased with plant density within the range of few to 10 to 15 plants/m of row and then declined steadily as plant density increased to about 30 plants $/ \mathrm{m}$ of row. The strong influence of inoculum rates on plant density and whitehead counts for the pulverized inoculum in the seed row, and the small effect of inoculum rate on plant density and whiteheads, led to the conclusion that further studies would be conducted with the whole millet grain inoculum system.

During the second winter wheat crop year (1996 to 1997) at Pendleton, the percentage of whiteheads but not seedling density was significantly $(P<0.0001)$ affected by the four rates of millet seed inoculum. Percentages of whiteheads were $0.3,2.3,3.6$, and $4.9 \%$ for the inoculum treatments of $0,0.5,1.6$, and $4.0 \mathrm{~g} / \mathrm{m}$ of row, respectively $\left(\mathrm{LSD}_{0.05}=1.4\right)$. 
Fungicide seed treatments. Treatment of winter wheat seed with either benomyl or difenoconazole plus mefenoxam at Echo during the 1997 to 1998 crop year did not affect the expression of whiteheads in noninoculated control plots or in plots inoculated with a mixture of five isolates of $F$. pseudograminearum. Each of the three fungicide treatments had means of $0.8 \%$ whiteheads in the noninoculated treatment and 6.1 to $6.2 \%$ whiteheads in the inoculated treatment. The inoculum effect was significant $\left(P<0.0001 ; \mathrm{LSD}_{0.05}=1.0\right)$.

Percentages of whiteheads at Moro during the 2001 to 2002 crop year were significantly influenced by inoculation $(P<0.0001)$ but not seed treatment $(P=0.3658)$ or the interaction of those factors $(P=0.4291)$. Mean percentages of whiteheads in the control and inoculated treatments averaged 10.3 and $30.8 \%$, respectively $\left(\mathrm{LSD}_{0.05}=\right.$ 3.4). The difference between the percentage of whiteheads did not differ in untreated and difenoconazole plus mefenoxam treatments in noninoculated $(14.9 \pm 1.7$ versus $14.1 \pm 2.4)$ or inoculated $(31.0 \pm$ 6.1 versus $36.9 \pm 0.5)$ plots.

Starter fertilizer and root-zone tillage. Initial analysis of the eight treatments by one-way analysis of variance indicated that the main effect of year was not significant $(P<0.35)$ for seedling density, grain test weight, percentage of whiteheads, severity rating for subcrown internode lesions, and percentages of crowns with a browning of internal tissue. Grain yield was slightly greater $(P=0.03)$ during 1997 than $1998\left(1,688.7\right.$ versus $\left.1,572.4 \mathrm{~kg} / \mathrm{ha} ; \mathrm{LSD}_{0.05}=104.8\right)$. Subcrown internode lesions were also more prevalent $(P=0.03)$ during the first than second year (32.5 versus $26.1 \%$; $\left.\mathrm{LSD}_{0.05}=5.6\right)$. Data over years were therefore combined and the experiment was analyzed as a randomized complete block with main effects of starter fertilizer, root-zone tillage, and inoculation. Seedling density did not differ among treatments.

Whiteheads differed significantly $(P<0.0001)$ for all three main effects and the starter fertilizer $\times$ root-zone tillage interaction. The interaction indicated that the starter fertilizer caused a relatively greater increase in the percentage of whiteheads when the drill opener that disrupted soil under the seed was used (5.4\%) compared with the drill opener that did not disrupt soil under the seed (3.3\%). Main effects indicated that whiteheads were greater when soil was disrupted under the seed than when it was not disrupted (4.1 versus $2.9 \%$ ), when starter fertilizer was applied rather than not applied (5.7 versus $1.4 \%$ ), and when additional inoculum was applied compared with not applied (4.1 versus 3.0\%). Treatments having the greatest percentage of whiteheads were those that were both inoculated and fertilized (Table 1) regardless of whether they had root-zone tillage $(7.3 \%)$ or not $(6.4 \%)$. Treatments with the least whiteheads were those that did not receive starter fertilizer or root-zone tillage regardless of whether they were inoculated $(0.5 \%)$ or not $(0.6 \%)$.

Percentages of plants with lesions on subcrown internodes differed significantly for the main effects of inoculation $(P<0.0001)$ and starter fertilizer $(P=0.0037)$ and for the interactions of starter fertilizer $\times$ inoculation $(P=0.0241)$ and root-zone tillage $\times$ starter fertil$\operatorname{izer}(P=0.0427)$. For interactions, the inoculation caused a relatively greater increase in the percentage of lesions when starter fertilizer was applied (20.0\%) than when not applied (10.8\%) and a slightly greater increase by root-zone tillage when starter fertilizer was not applied (5.0\%) than when applied (3.3\%). For main effects, lesions were more prevalent when starter fertilizer was not applied than applied (32.4 versus $26.2 \%)$ and when plots were inoculated than not inoculated (37.1 versus $21.5 \%$ ). Although the main effect of rootzone tillage was not significant $(P=0.6564)$, Table 1 shows that the four treatments with root-zone disruption had numerically higher percentages of subcrown lesions (36 to 39\%) than the four treatments that did not receive root-zone tillage (13 to $31 \%$ ). The treatment with the fewest lesions (13\%) received starter fertilizer but not root-zone tillage or inoculum of $F$. pseudograminearum.

Severity ratings for lesions on subcrown internodes followed a pattern similar to that for percentages of affected plants. Lesion severity differed significantly for the main effects of inoculation $(P=0.0002)$ and starter fertilizer $(P<0.0001)$ and for the interaction of root-zone tillage $\times$ starter fertilizer $(P=0.0022)$. For the interaction, the starter fertilizer caused a relatively greater increase in severity rating in plots with root-zone tillage (increase of 1.3 rating units) than when soil under the seed was not disrupted ( 0.2 units). For main effects, mean lesion severity ratings were higher when starter fertilizer was applied than not applied (3.3 versus 2.5) and when plots were inoculated than not inoculated ( 3.2 versus 2.6 ). The treatment with the highest severity rating (3.6) received inoculum, starter fertilizer, and root-zone tillage (Table 1). The treatment with the lowest severity rating (1.7) was inoculated but did not receive starter fertilizer or root-zone tillage.

Plants with a visual browning of the internal crown tissue at the time of sampling were influenced by the main effects of starter fertilizer $(P=$ $0.0001)$ and inoculation $(P<0.0001)$. No interaction of main effects was significant $(P>0.48)$. Brown crowns were more prevalent when starter fertilizer was applied than not applied (24.5 versus $19.1 \%)$ and when plots were inoculated than not inoculated (27.9 versus $15.6 \%$ ). Treatments with the highest percentages of rotting crowns received both starter fertilizer and root-zone tillage (Table 1), regardless of whether inoculum was applied (32.5\%) or not applied (30.0\%). Treatments with the lowest percentages of brown crowns did not receive starter fertilizer or root-zone tillage, regardless of whether inoculum was applied (14.5\%) or not applied (13.0\%).
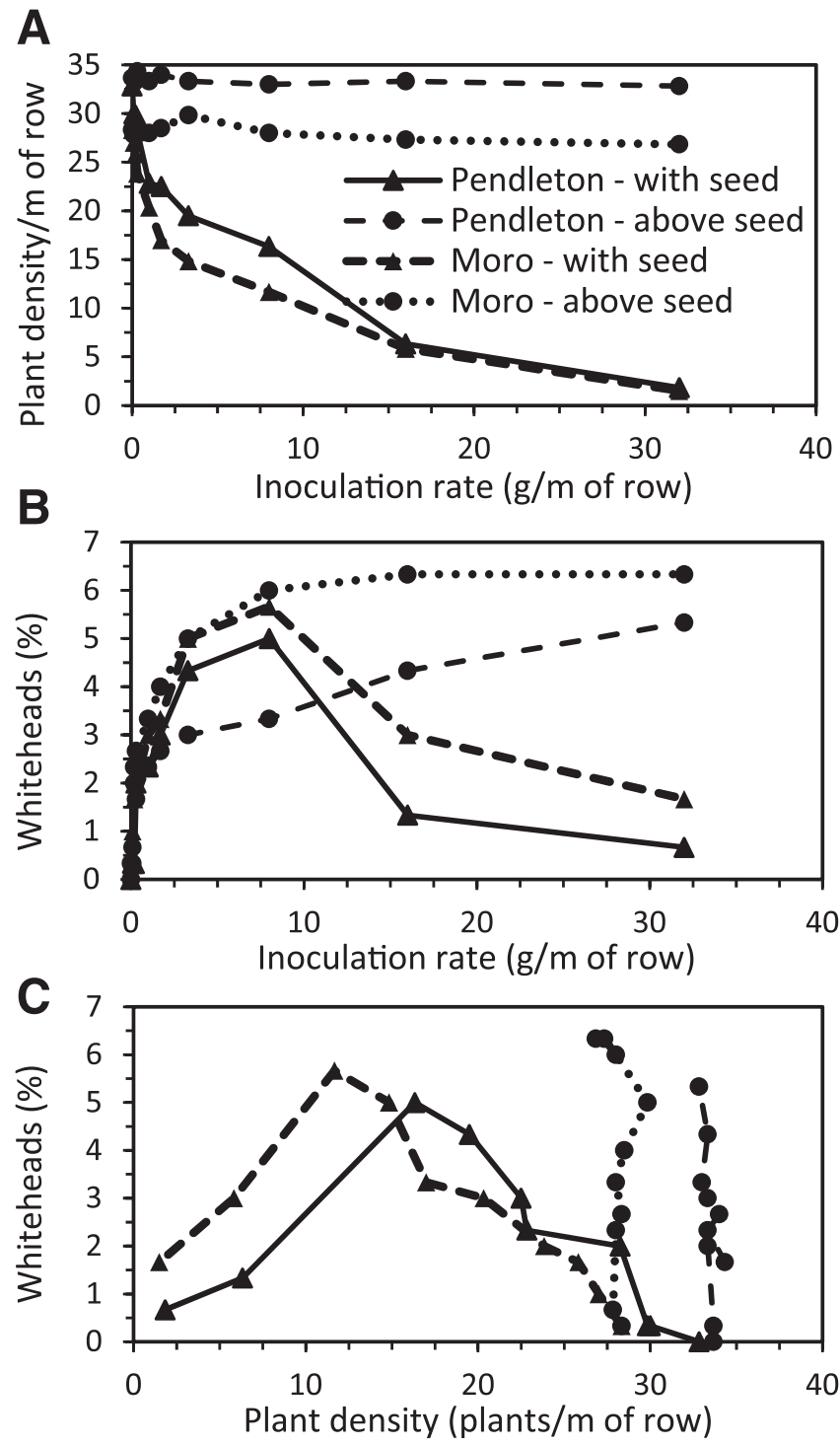

Fig. 2. Associations between placement and rate (in grams per meter of row) of Fusarium pseudograminearum inoculum on $\mathbf{A}$, plant density, $\mathbf{B}$, percentage of whiteheads, and $\mathbf{C}$, relationship between plant density and whiteheads for winter wheat cultivar Rod planted at Pendleton and Moro in Oregon. Inoculum placed with the seed consisted of pulverized wheat plus oats dispensed as a mixture with the wheat seed. Inoculum placed above the seed consisted of whole millet seeds placed $2 \mathrm{~cm}$ above the wheat seed. 
Grain yield was significantly increased by the application of starter fertilizer $\left(1,730\right.$ versus $\left.1,531 \mathrm{~kg} / \mathrm{ha}, P=0.0001, \operatorname{LSD}_{0.05}=95\right)$ and decreased by root-zone tillage $(1,569$ versus $1,692 \mathrm{~kg} / \mathrm{ha}, P=$ 0.0118 ) but was not influenced by the inoculation treatment or any interaction among main effects. However, it was evident in Table 1 that grain yield tended to be reduced by inoculation where starter fertilizer was not applied (means of 1,634 and 1,428 kg/ha for noninoculated and inoculated treatments, respectively), but not where inoculum had been applied (means of 1,750 and $1,710 \mathrm{~kg} / \mathrm{ha}$ ). This positive influence of starter fertilizer was apparent (Table 1) even though pairs of fertilized versus not fertilized treatments differed significantly for only the two comparisons in inoculated plots. Grain test weight (Table 1) was not significantly affected by any main effect or their interactions.

Correlations were positive and significant for associations between the percentage of whiteheads and the severity of subcrown internode lesions $\left(P<0.0001, R^{2}=0.22, n=80\right)$, percentage of crowns with internal rotting $\left(P=0.0001, R^{2}=0.19\right)$ and grain yield $(P=$ $\left.0.0062, R^{2}=0.09\right)$, but not between whiteheads and percentage of plants with subcrown internode lesions $(P=0.45)$ or grain test weight $(P=0.80)$. Plots of significant correlations revealed that none of the relationships appeared to be of biological importance, and none were significant when correlations were conducted separately for inoculated and noninoculated treatments.

\section{Discussion}

A mechanized system is described for placing precise inoculum units of Fusarium crown rot pathogens above the wheat seed during a single pass of a seed drill. The inoculation system involves metering presterilized, pathogen-recolonized whole millet seeds from a fertilizer distributor mounted on a small-plot grain drill. The uniformly sized, spherical inoculum units and the wheat seed are dropped through separate tubes and deposited at different depths in the soil. By placing the inoculum directly above the wheat seed, the wheat coleoptile is forced to emerge through the zone of pathogen infestation, closely approximating the natural system in which the pathogen survives between crops in straw and crown segments that were infested when the plant was still living. Wheat seed is metered through a standard revolving cone distributor on the drill, allowing cultivars or other treatments to be changed at specific regular intervals. The mechanized inoculation system could be disabled rapidly by simply removing the chain that powers the distributor (Fig. 1B), without the need to remove inoculum from the distributor when inoculum delivery was not desired.

Experiments reported in this work consisted of adjacent plantings of a wheat cultivar for which the four-row plots were either inoculated or not inoculated. This configuration allowed side-by-side comparisons of the inoculum treatments. However, this experimental design requires large blocks of land when $>20$ cultivars or other treatments are being compared. When there were large numbers of replicates (more than five) and/or large numbers of cultivars $(>20)$, the inoculum delivery system was generally modified by blocking two of the distributor's metering wheels (Fig. 1F). This produced two-row plots (two inoculated and two controls within each fourrow replicate), which reduced the overall experimental size by $50 \%$ (Smiley 2019; Smiley et al. 2002, 2005b). The pairs of inoculum treatments planted at $36-\mathrm{cm}$ row spacing were easily harvested as two-row plots using the same small-plot combine used for fourrow plots. The two-row plots may have also reduced the variability among replicates that is common when cultivars are screened for tolerance to Fusarium crown rot in fields naturally infested with a crown rot pathogen (Smiley and Yan 2009).

This mechanized planting and inoculation system was just as easily modified to examine tolerances of small grain cereals to plantparasitic nematodes (Smiley 2009b; Smiley et al. 2012). This use was achieved by dispensing a granular nematicide below the seed using the process described for the starter fertilizer experiment. The John Deere HZ drill with hoe-type row openers and press wheels was equally effective for planting deeply into cultivated stubblemulch tillage systems (Fig. 1G) and also for planting into highresidue no-till systems with either standing or flail-mowed stubble (Fig. 1H). A further use of this drill system involved more complex factorial experiments involving cultivar, fertilizer, and inoculum treatments (R. W. Smiley, unpublished data). This was achieved by making multiple passes through the experimental area to dispense the deepest treatment first (as for starter fertilizer or nematicide) and more shallow treatments in succession (as for seed and/or inoculum). Any of these dry materials could be dispensed either through the revolving cone or the fertilizer distributor, depending on the design of the experiment. Another application for this drill was to apply a precision top-dressing (e.g., fertilizer, nematicide, or inoculum) to all or selected drill rows of winter wheat without treating the interrow space. The top-dressings during spring were conducted without damaging winter wheat planted up to 5 months earlier (in a region where wheat is semidormant for at least 3 months during midwinter). The deep-furrow drill tracked very well as a result of depressed rows, limited side-to-side sway allowance by the three-point hitch, all drill rows being inside the tractor's wheel tracks, and the relative ease for a tractor driver to exactly follow tire tracks formed during previous trips through the experiment.

The whole millet seed inoculum, when placed above the wheat seed, was superior to a pulverized grain inoculum substrate mixed and dispensed with the wheat seed. The pulverized grain substrate consisted of a plethora of particle shapes and sizes that could only be distributed manually or as a mixture with the wheat seed. The pulverized substrate could not be metered effectively through a fertilizer distributor as a result of bridging above the metering mechanism and the presence of static electricity that causes the smallest particles to

Table 1. Measures of Fusarium crown rot and wheat grain yield and quality as influenced by inoculation of soil with a mixture of six Fusarium pseudograminearum isolates on millet seed substrate, application of starter fertilizer placed with the wheat seed (with) or $2 \mathrm{~cm}$ below the seed (below), and shallow disturbance of soil under the wheat seed at the time of planting (root-zone tillage) ${ }^{\mathrm{z}}$

\begin{tabular}{|c|c|c|c|c|c|c|c|c|}
\hline \multirow[b]{2}{*}{ Inoculated } & \multirow[b]{2}{*}{$\begin{array}{c}\text { Starter fertilizer } \\
\text { and placement }\end{array}$} & \multirow[b]{2}{*}{$\begin{array}{c}\text { Root-zone } \\
\text { tillage }\end{array}$} & \multirow[b]{2}{*}{$\begin{array}{l}\text { Whiteheads } \\
\text { (\% heads) }\end{array}$} & \multicolumn{2}{|c|}{ Subcrown internode lesions } & \multirow[b]{2}{*}{$\begin{array}{l}\text { Brown crowns } \\
\text { (\% plants) }\end{array}$} & \multirow[b]{2}{*}{$\begin{array}{c}\text { Grain yield } \\
\text { (kg/ha) }\end{array}$} & \multirow[b]{2}{*}{$\begin{array}{c}\text { Grain test } \\
\text { weight (g/liter) }\end{array}$} \\
\hline & & & & $\begin{array}{l}\text { Incidence } \\
\text { (\% plants) }\end{array}$ & $\begin{array}{c}\text { Severity } \\
\text { (index: 0-4) }\end{array}$ & & & \\
\hline No & None & No & $0.6 \pm 0.2 \mathrm{e}$ & $31.0 \pm 3.1 \mathrm{ab}$ & $2.6 \pm 0.2 \mathrm{~b}$ & $13.0 \pm 2.8 \mathrm{f}$ & $1,666.8 \pm 106.5 \mathrm{a}$ & $772.0 \pm 4.4 \mathrm{a}$ \\
\hline No & None & Yes & $2.2 \pm 0.2 \mathrm{~d}$ & $39.0 \pm 3.1 \mathrm{a}$ & $3.1 \pm 0.2 \mathrm{ab}$ & $23.0 \pm 2.1 \mathrm{~cd}$ & $1,601.3 \pm 110.8 \mathrm{ab}$ & $770.9 \pm 4.4 \mathrm{a}$ \\
\hline No & With & No & $4.1 \pm 0.04 \mathrm{c}$ & $12.5 \pm 2.3 \mathrm{~d}$ & $2.7 \pm 0.4 \mathrm{~b}$ & $17.0 \pm 1.1 \mathrm{ef}$ & $1,767.5 \pm 59.9 \mathrm{a}$ & $776.3 \pm 2.3 \mathrm{a}$ \\
\hline No & Below & Yes & $4.8 \pm 0.4 \mathrm{c}$ & $36.5 \pm 2.6 \mathrm{a}$ & $3.5 \pm 0.2 \mathrm{a}$ & $30.0 \pm 1.7 \mathrm{ab}$ & $1,732.3 \pm 59.9 \mathrm{a}$ & $775.1 \pm 2.4 \mathrm{a}$ \\
\hline Yes & None & No & $0.5 \pm 0.1 \mathrm{e}$ & $23.0 \pm 3.9 \mathrm{bc}$ & $1.7 \pm 0.2 \mathrm{c}$ & $14.5 \pm 2.0$ ef & $1,451.3 \pm 70.8 \mathrm{bc}$ & $774.3 \pm 1.9 \mathrm{a}$ \\
\hline Yes & None & Yes & $2.2 \pm 0.2 \mathrm{~d}$ & $36.6 \pm 3.0 \mathrm{a}$ & $2.6 \pm 0.1 \mathrm{~b}$ & $26.0 \pm 1.5 \mathrm{bc}$ & $1,405.4 \pm 70.6 \mathrm{c}$ & $773.3 \pm 1.9 \mathrm{a}$ \\
\hline Yes & With & No & $6.4 \pm 0.4 b$ & $19.5 \pm 3.3 \mathrm{~cd}$ & $3.2 \pm 0.3 \mathrm{ab}$ & $18.5 \pm 2.0 \mathrm{de}$ & $1,733.4 \pm 52.4 \mathrm{a}$ & $773.6 \pm 2.8 \mathrm{a}$ \\
\hline Yes & Below & Yes & $7.3 \pm 0.4 \mathrm{a}$ & $36.2 \pm 1.3 \mathrm{a}$ & $3.6 \pm 0.2 \mathrm{a}$ & $32.5 \pm 1.4 \mathrm{a}$ & $1,686.6 \pm 50.6 \mathrm{a}$ & $772.5 \pm 2.9 \mathrm{a}$ \\
\hline Mean & & & 3.5 & 29.3 & 2.9 & 21.8 & $1,630.6$ & 773.5 \\
\hline$F>P$ & & & $<0.0001$ & $<0.0001$ & $<0.0001$ & $<0.0001$ & 0.0009 & 0.8998 \\
\hline $\operatorname{LSD}_{0.05}$ & & & 0.9 & 8.3 & 0.7 & 5.1 & 5.1 & ns \\
\hline
\end{tabular}

${ }^{\mathrm{z}}$ Means followed by the same letter within a column did not differ at $P=0.05$ according to Fisher's least significant difference test. LSD $\mathrm{D}_{0.05}=$ Fisher's least significant difference. 
adhere to the inside of drop tubes that connect the fertilizer distributor to the furrow opener. When inoculum was coarsely ground and mixed with the seed, seedling emergence was under certain circumstances greatly reduced by damping-off even when the $F$. pseudograminearum inoculum was applied at very low rates. When plant density was reduced by damping-off, surviving plants were also infected but failed to express whiteheads because the surviving plants apparently had greater access to water, nutrients, and light, compared with plants in denser stands.

The whole millet seed inoculation method with nearly spherical inoculum units was effective for inducing additional crown rot of adult plants and was much safer than the pulverized inoculum placed with the wheat seed, and the number of inoculum units (foci) dispensed per unit area was much easier to quantify. A given rate of inoculum in these studies produced different levels of disease at two locations that differed in the amount of seasonal rainfall.

Comparison of the two inoculation systems showed that the incidence of wheat whiteheads varied depending on the density and placement of inoculum with respect to the location of wheat seed, crop years (weather variables), plant density (competition for resources such as water), application of starter fertilizer, and the style of drill opener. Many interactions among these factors were also identified.

Occurrences of whiteheads are affected by conditions that affect the rate of water extraction and transmission into the foliage during the growing season (Burgess et al. 1993, 2001; Cook 2017; Dodman and Wildermuth 1987; Klassen et al. 1992; Klein et al. 1991; Smiley 2009a; Smiley et al. 2005a). In low precipitation areas, more whiteheads are expressed when application rates of preplant nitrogen fertilizer are increased, leading to more rapid plant growth and greater early-season extraction of water from soil (Cook 1981, 2017; Papendick and Cook 1974).

In experiments reported here, whiteheads were not significantly correlated with other measures of crown rot, including incidence and severity of lesions on subcrown internodes and rotting of crown tissue. Likewise, whiteheads in these experiments were not correlated with browning of the sheath of the first-formed leaf (data not reported). Numerous publications report either whiteheads, lesions of subcrown internodes, rotting of crowns, or browning of the leaf sheath as a single measure of crown rot incidence or severity. This research demonstrated that these visible symptoms are not always closely related in the Pacific Northwest. It is presumed that there may be a stronger influence of water stress and perhaps other edaphic factors on the formation of whiteheads at the end of the season compared with a lesser influence of these factors on initial infection and development of symptoms on seedling crowns and subcrown internodes.

Hollaway et al. (2013) reported that the density of Fusarium DNA in soil before planting tends to be more highly correlated with the browning of basal culms than with the occurrence of whiteheads. Purss (1966) and Knight et al. (2017) demonstrated that F. pseudograminearum could colonize stems of wheat without causing visual symptoms such as browning of basal internodes or occurrence of whiteheads. Knight et al. (2017) further demonstrated that the extent to which vascular tissue was colonized by Fusarium species was much greater in stems that became prematurely senesced (whiteheads) compared with stems on which the heads senesced normally. After the pathogen invades the root or crown tissue, the xylem in the basal internodes was the first and most frequently tissue to become colonized (Knight et al. 2017). After it colonized the xylem, the pathogen moved more fully into the phloem of stems that produced whiteheads. Knight et al. (2017) therefore suggested that the pathogen was likely involved in disruption of sugar flow in stems with whiteheads, as well as disruption of water flow in stems with and without whiteheads. Knight et al. (2017) concluded that the determining factor for whether a wheat head senesced naturally or prematurely may be associated with the proportion of vascular bundles that become colonized by the pathogen. Their observations showed differences between two cultivars studied, supporting observations that the progress of disease in the basal internodes and the expression of whiteheads may vary individually in response to variables of cultivar, pathogen species, pathogen isolate virulence, and environment. Knight and Sutherland (2015) also showed that browning of the basal internodes was more significantly correlated with the mass of fungal mycelium in those culms when the measurements were made at a time when plants were in the anthesis growth stage rather than later measurements at the time of harvest. Most reports of culm browning, including this article, were based on stem samples collected at the time of harvest.

Whiteheads were not significantly correlated with grain test weight. The converse might be predicted since the test weight is dramatically reduced in stems that produce whiteheads (Smiley and Patterson 1996; Smiley et al. 2005b). It is very likely that shriveled grains, which are of very light weight, were separated from the stream of plump kernels by the combine's fan and blown out with the grain chaff. Some or many of the shriveled kernels from whiteheads were therefore likely to have been lost from the grain sample used to measure grain yield and test weight.

These experiments provided additional insights into procedures that can increase the severity of crown rot in field trials. This is important because in naturally infested fields, crown rot often occurs at a level of intensity too low to separate the importance of experimental treatments. It was shown in these trials that the incidence of whiteheads increased over the background level caused by native Fusarium populations when inoculum of $F$. pseudograminearum was added to soil that was also treated with starter fertilizer. However, there was no influence of the added inoculum in soils that did not receive starter fertilizer. It is expected that this relationship would vary in accordance with native disease pressure, amount of inoculum added, and possibly other factors. Moreover, this research demonstrated that it was very important to calibrate the rate of inoculum to enhance disease without causing seedling damping-off. The optimal rate of inoculation is likely to vary for each climatic region and farming system.

Percentages of whiteheads were increased by applying starter fertilizer and were greater when the fertilizer was placed below the seed rather than directly in the seed zone. Similar results were found by monitoring the severity of lesions on subcrown internodes. Modern seed drills have the capacity to deliver the majority of the fertilizer for the crop between seed rows and to deliver a different fertilizer at much lower rates directly into the seed zone or at various locations below or beside the seed. When fertilizer is placed below the seed, the first-formed seminal roots are likely to penetrate the fertilizer band within a day after seed germination. However, since the seminal roots are oriented at a near vertical angle, access to the fertilizer may be considerably delayed when the fertilizer is placed in the seed zone of wheat planted with the deep-furrow drill in the semiarid Pacific Northwest. Nutrients placed in the seed zone would need to move downward into the root zone through mass flow or diffusion before becoming available to the first-formed seminal roots, which is unlikely because of a lack of rainfall soon after most wheat plantings in the semiarid Pacific Northwest. Alternatively, without rainfall soon after planting, the nutrients would become available when coronal roots begin to develop near the soil surface at the time when wheat plants reach the three-leaf stage (Klepper et al. 1984; Rickman and Klepper 1991). In this research, starter fertilizer caused an increase in whiteheads while also causing an increase in grain yield. Whiteheads were not indicative of a reduction in grain yield. This research provided support for the concept of increasing wheat yield by applying a starter fertilizer, regardless of where that fertilizer is placed in or near the seed zone.

It was previously reported that crown rot in inoculated experiments was not affected by treatment of wheat seed with benomyl (Wildermuth and McNamara 1994). The present research extended that observation to include treatment of seed with difenoconazole plus mefenoxam. The potential impact of other seed treatments should also be evaluated in preliminary field trials to determine whether they reduce the expression of crown rot.

This research also supported the suggestion that an optimal inoculation procedure for field studies involves placing inoculum above the 
seed to force the coleoptile to pass through the band of inoculum (Wildermuth and McNamara 1994). This process closely simulates the location of natural inoculum consisting of stubble segments of plant crowns that were infected during the production of the previous wheat crop.

Future experiments in the semiarid Pacific Northwest should be conducted by delivering a mixture of Fusarium isolates on infested whole millet seeds banded several centimeters above the seed at the lowest effective rate for the climatic zone and farming system. Since isolate aggressiveness differs in response to unknown environmental conditions, it appears preferable to inoculate soils with a mixture of isolates that express a range of aggressiveness levels in initial assays, rather than to utilize only a single highly aggressive isolate. Also, where wheat is to be planted rather deeply with a deepfurrow drill in the Pacific Northwest, the optimal inoculation rate was estimated to be $2.3 \mathrm{~g}$ of millet/m of row, equating to about 460 infested seeds $/ \mathrm{m}$ of row. The expression of disease could be amplified further by placing starter fertilizer with or below the wheat seed but that practice also improved grain yield in a way that was not closely related to the expression of whiteheads as a measure of Fusarium crown rot. When small-plot drills with a revolving cone are not able to be modified with a fertilizer distributor for on-thego simultaneous delivery of wheat seed and millet seed inoculum, the wheat seed can be planted deeply and the inoculum can then be distributed more shallowly during a second pass of the seed drill.

\section{Acknowledgments}

The author appreciates assistance from Oregon farmers who hosted experiments on their farms.

\section{Literature Cited}

Alahmad, S., Simpfendorfer, S., Bentley, A. R., and Hickey, L. T. 2018. Crown rot of wheat in Australia: Fusarium pseudograminearum taxonomy, population biology and disease management. Australas. Plant Pathol. 47:285-299.

Burgess, L. W., Backhouse, D., Summerell, B. A., and Swan, L. J. 2001. Crown rot of wheat. Pages 271-294 in: Fusarium. B. A. Summerell, J. F. Leslie, D. Backhouse, W. L. Bryden, and L. W. Burgess, eds. American Phytopathological Society, St. Paul, MN.

Burgess, L. W., and Liddell, C. M. 1983. Laboratory Manual for Fusarium Research. University of Sydney, Sydney, Australia.

Burgess, L. W., Summerell, B. A., Beddis, A. L., Backhouse, D., and Nelson, K. E. 1993. Environmental and management factors affecting the crown rot fungus, Fusarium graminearum Group 1, in Australia. Hodowla Roślin Aklimtyzacja i Nasiennictwo 37:25-33.

Cook, R. J. 1968. Fusarium root and foot rot of cereals in the Pacific Northwest. Phytopathology 58:127-131.

Cook, R. J. 1980. Fusarium foot rot of wheat and its control in the Pacific Northwest. Plant Dis. 64:1061-1066.

Cook, R. J. 1981. Fusarium diseases of wheat and other small grains in North America. Pages 39-52 in: Fusarium: Diseases, Biology and Taxonomy. P. E. Nelson, T. A. Toussoun, and R. J. Cook, eds. Pennsylvania State University Press, University Park.

Cook, R. J. 2017. Untold Stories: Forty Years of Field Research on Root Diseases of Wheat. American Phytopathological Society, St. Paul, MN.

Dodman, R. L., and Wildermuth, G. B. 1987. Inoculation methods for assessing resistance in wheat to crown rot caused by Fusarium graminearum Group 1. Aust. J. Agric. Res. 38:473-486.

Hollaway, G. J., Evans, M. L., Wallwork, H., Dyson, C. B., and McKay, A. C. 2013. Yield loss in cereals, caused by Fusarium culmorum and F. pseudograminearum, is related to fungal DNA in soil prior to planting, rainfall, and cereal type. Plant Dis. 97:977-982.

Kane, R. T., Smiley, R. W., and Sorrells, M. E. 1987. Relative pathogenicity of selected Fusarium species and Microdochium bolleyi to winter wheat in New York. Plant Dis. 71:177-181.

Klassen, J. A., Matthee, F. N., Marasas, W. F., and van Schalkwyk, D. J. 1992. Survey of Fusarium species associated with crowns of healthy-head and whitehead wheat plants in the southern and western Cape Province. Phytophylactica 24:85-94.

Klein, T. A., Burgess, L. W., and Ellison, F. W. 1991. The incidence and spatial patterns of wheat plants infested by Fusarium graminearum Group 1 and the effect of crown rot on yield. Aust. J. Agric. Res. 42:399-407.

Klepper, B., Belford, R. K., and Rickman, R. W. 1984. Root and shoot development in winter wheat. Agron. J. 76:117-122.

Knight, N. L., Macdonald, B., and Sutherland, M. W. 2017. Colonization of durum wheat (Triticum turgidum L. var. durum) culms exhibiting premature senescence (dead heads) associated with Fusarium pseudograminearum crown rot. Plant Dis. 101:1788-1794.

Knight, N. L., and Sutherland, M. W. 2015. Culm discolouration as an indicator of Fusarium pseudograminearum biomass. Australas. Plant Pathol. 44:319-326.

Liddell, C. M., Burgess, L. W., and Taylor, P. W. J. 1986. Reproduction of crown rot of wheat caused by Fusarium graminearum Group 1 in the greenhouse. Plant Dis. 70:632-635.

Nelson, P. E., Toussoun, T. A., and Marasas, W. F. O. 1983. Fusarium Species: An Illustrated Manual for Identification. Pennsylvania State University Press, University Park.

Ogg, A. G., Jr., Smiley, R. W., Pike, K. S., McCaffrey, J. P., Thill, D. C., and Quisenberry, S. S. 1999. Integrated pest management for conservation systems. Pages 97-128 in: Advances in Conservation Farming. E. L. Michalson, R. I. Papendick, and J. E. Carlson, eds. CRC Press, Boca Raton, FL.

Papendick, R. I., and Cook, R. J. 1974. Plant water stress and development of Fusarium foot rot in wheat subjected to different cultural practices. Phytopathology 64:358-363.

Poole, G. J., Smiley, R. W., Walker, C., Huggins, D., Rupp, R., Abatzoglou, J., Garland-Campbell, K., and Paulitz, T. C. 2013. Effect of climate on the distribution of Fusarium spp. causing crown rot of wheat in the Pacific Northwest of the United States. Phytopathology 103:1130-1140.

Purss, G. S. 1966. Studies of varietal resistance to crown rot of wheat caused by Fusarium graminearum Schw. Queensl. J. Agric. Anim. Sci 23:475-498.

Rickman, R. W., and Klepper, B. 1991. Environmentally driven cereal crop growth models. Annu. Rev. Phytopathol. 29:361-380.

Schillinger, W. R., Papendick, R. I., Guy, S. O., Rasmussen, P. E., and van Kessel, C. 2006. Dryland cropping systems in the western United States. Pages 365-393 in: Dryland Agriculture, 2nd ed. G. A. Peterson, P. W. Unger, and W. A. Payne, eds. Agronomy Monograph 23. American Society of Agronomy, Madison, WI

Smiley, R., Peterson, J., Gourlie, J., Whittaker, R., Patterson, L., Easley, S., Thompson, D., Rhinhart, K., and Riera-Lizarazu, O. 2002. Influence of Fusarium crown rot on yield of winter and spring wheat. Biol. Cult. Tests Control Plant Dis. 17:S07.

Smiley, R. W. 1996. Diseases of wheat and barley in conservation cropping systems of the semiarid Pacific Northwest. Am. J. Altern. Agric. 11:95-103.

Smiley, R. W. 2009a. Water and temperature parameters associated with winter wheat diseases caused by soilborne pathogens. Plant Dis. 93:73-80.

Smiley, R. W. 2009b. Root-lesion nematodes reduce yield of intolerant wheat and barley. Agron. J. 101:1322-1335.

Smiley, R. W. 2019. Fusarium crown rot whitehead symptom as influenced by wheat crop management and sampling date. Plant Dis. Published online 29 April 2019. https://doi.org/10.1094/PDIS-01-19-0226-RE

Smiley, R. W., Backhouse, D., Lucas, P., and Paulitz, T. C. 2009. Diseases which challenge global wheat production-Root, crown, and culm rots. Pages 125-153 in: Wheat: Science and Trade. B. F. Carver, ed. Wiley-Blackwell, Ames, IA.

Smiley, R. W., Collins, H. P., and Rasmussen, P. E. 1996. Diseases of wheat in long-term agronomic experiments at Pendleton, Oregon. Plant Dis. 80:813-820.

Smiley, R. W., Gourlie, J. A., Easley, S. A., and Patterson, L.-M. 2005a Pathogenicity of fungi associated with the wheat crown rot complex in Oregon and Washington. Plant Dis. 89:949-957.

Smiley, R. W., Gourlie, J. A., Easley, S. A., Patterson, L.-M., and Whittaker, R. G. 2005 b. Crop damage estimates for crown rot of wheat and barley in the Pacific Northwest. Plant Dis. 89:595-604.

Smiley, R. W., Gourlie, J. A., Rhinhart, K. E. L., Marshall, J. M., Anderson, M. D., and Yan, G. P. 2012. Influence of nematicides and fungicides on spring wheat in fields infested with soilborne pathogens. Plant Dis. 96:1537-1547.

Smiley, R. W., Machado, S., Gourlie, J. A., Pritchett, L. C., Yan, G. P., and Jacobsen, E. E. 2013. Influence of semiarid cropping systems on root diseases and inoculum density of soilborne pathogens. Plant Dis. 97: 547-555.

Smiley, R. W., Machado, S., Rhinhart, K. E. L., Reardon, C. L., and Wuest, S. B. 2016. Rapid quantification of soilborne pathogen communities in wheat-based long-term field experiments. Plant Dis. 100:1692-1708.

Smiley, R. W., and Patterson, L.-M. 1996. Pathogenic fungi associated with Fusarium foot rot of winter wheat in the semiarid Pacific Northwest. Plant Dis. 80:944-949.

Smiley, R. W., and Yan, H. 2009. Variability of Fusarium crown rot tolerances among cultivars of spring and winter wheat. Plant Dis. 93:954-961.

Summerell, B. A., Burgess, L. W., and Klein, T. A. 1989. The impact of stubble management on the incidence of crown rot of wheat. Aust. J. Exp. Agric. 29: 91-98.

Vogel, K. P. 1978. A simple method of converting rangeland drills to experimental plot seeders. J. Range Manage. 31:235-237.

Wildermuth, G. B., and McNamara, R. B. 1994. Testing wheat seedlings for resistance to crown rot caused by Fusarium graminearum Group 1. Plant Dis. 78:949-953

Williams, K. J., Dennis, J. I., Smyl, C., and Wallwork, H. 2002. The application of species-specific assays based on the polymerase chain reaction to analyse Fusarium crown rot of durum wheat. Australas. Plant Pathol. 31:119-127. 